\title{
Funcionamiento de un quirófano de quemados en pandemia por coronavirus
}

\author{
Operation of an operating room for burns in a pandemic \\ due to coronavirus
}

\author{
María E. Calderón González², Carolina Soto Diez², Adriana Alzate Rodas², \\ Marco A. Ríos Vergara², Ekaterina Troncoso Olchevskaia², Carla Ibarra Mujica², \\ Nicolás Flores Moltedo², Claudio Thomas Bas², Manuel Calcagno Lüer ${ }^{3}$, \\ Roberto Macchiavello Macho³, Manuel Lilllo Cáceres ${ }^{3}$, Jimena Doña Vial ${ }^{3}$, Enrica Ramírez Pittaluga ${ }^{3}$
}

\section{RESUMEN}

La actual pandemia por coronavirus afecta a pacientes de todas las edades y estratos socioeconómicos, los accidentes por quemaduras también. Las cirugías de urgencia y el manejo quirúrgico del gran quemado no pueden ser diferidos, por lo que en el presente artículo mostramos la experiencia y organización del Servicio de Quemados del Hospital de Urgencia de Asistencia Pública para manejar a los pacientes COVID-19 (+) y (-) que se encuentran actualmente en nuestra Unidad.

Palabras claves: SARS-CoV-2, paciente gran quemado

\begin{abstract}
The current coronavirus pandemic affects patients of all ages and socio-economic strata, burn accidents as well. The emergency surgeries and the surgical management of the large burn cannot be delayed, so in this article we show the experience and organization of the Emergency Hospital Burn Service of Public Assistance to manage patients COVID-19 (+) and $(-)$ who are currently in our Unit.

Keywords: SARS-CoV-2, large burned patient.
\end{abstract}

REVISTA ARGENTINA DE CIRUGÍA PLÁSTICA 2020;26(2):84-87. HTTPS://DOI.ORG/10.32825/RACP/202002/0084-0087

\section{INTRODUCCIÓN}

El SARS-CoV-2, responsable actual de la mayor pandemia registrada en los últimos años, ha impactado a nivel mundial en todo sentido, con cerca de $2,7 \mathrm{mi}-$ llones de contagiados y 187.000 fallecidos en todo el mundo ${ }^{1}$. Latinoamérica ha debido enfrentarse con algunas semanas de desfase al mismo desafío, pero con sistemas de salud ya estresados, políticas públicas poco preparadas y una población que se resiste a cumplir con el "Quédate en casa".

El Hospital de Urgencias de Asistencia Pública es uno de los grandes Centros de Trauma de Santiago de Chile y lugar donde funciona el principal Centro de Referencia Nacional del Gran Quemado Adulto, creado hace 50 años. Cuenta con 1 Pabellón Quirúrgico dentro del Servicio, 10 camas de Cuidados Intensivos (in-

1. Jefa del Servicio de Quemados del Hospital de Urgencia de Asistencia Pública. Santiago de Chile.

2. Cirujano Plástico del Servicio de Quemados del Hospital de Urgencia de Asistencia Pública.

3. Cirujano General del Servicio de Quemados del Hospital de Urgencia de Asistencia Pública.

$\triangle$ Correspondencia: revista@sacper.org.ar

Los autores no declaran conflictos de intereses.

Recibido: 03/05/2020 / Aceptado: 05/05/2020 dividuales), 8 camas de Cuidados Intermedios (en sala común) y 4 camas de cuidados básicos (en sala común); lo que permite recibir cerca de 200 pacientes quemados por año derivados desde todo Chile y centrado en el manejo específico los casos más extensos y complejos catalogados como graves, críticos y sobrevida excepcional según la Clasificación de las Guías Ministeriales del manejo del Gran Quemado².

Pese a que el primer caso COVID (+) en Chile se presentó en la ciudad de Talca el 3 de marzo del 2020, y que como hospital nos fuimos preparando para la potencial ola de pacientes "respiratorios"; la súbita presencia de "un caso sospechoso" derivado hacia nuestro Servicio desde un hospital de región, a 1 mes después del caso índice en nuestro país; y su posterior confirmación junto a la de otros 4 pacientes más al día siguiente, nos obligó a instaurar rápidamente una organización "marcial" para mantener la frecuencia necesaria de aseos quirúrgicos, escarectomías, injertos y cuidados necesarios, en los ya frágiles pacientes quemados, así como del personal de salud que se encuentra a cargo de ellos.

\section{MATERIAL Y MÉTODOS}

El Servicio de Quemados cuenta con 22 camas: 10 de UCI, 8 de UTI y 4 de cuidados medios.

Actualmente tenemos seis pacientes quemados con 
TABLA 1. Planificación de la actividad quirúrgica en el Servicio de Quemados del HUAP.

\begin{tabular}{|c|c|}
\hline $\begin{array}{l}\text { División del equipo } \\
\text { de cirujanos }\end{array}$ & $\begin{array}{l}\text { - } \quad 13 \text { cirujanos: } 8 \text { cirujanos plásticos y } 5 \text { cirujanos generales divididos en } 2 \text { grupos de trabajo. } \\
\text { - } \quad \text { Cada grupo trabaja } 2 \text { semanas de manera alternada. } \\
\text { - } \quad \text { Jornadas de trabajo de } 9 \text { hs diarias, de lunes a viernes. } \\
\text { - } \quad \text { Cirujanos por día: } 3 \text { cirujanos staff + } 1 \text { residente de Cirugía. }\end{array}$ \\
\hline $\begin{array}{l}\text { Programación de } \\
\text { la tabla quirúrgica }\end{array}$ & $\begin{array}{l}\text { - } \quad \text { Se programarán } 2 \text { a } 3 \text { cirugías por día; en caso de paciente COVID-19 (+), este deberá realizarse a } 2 \text { da hora. } \\
\text { - } \quad \text { Cada cirugía debe durar un máximo de } 2 \text { hs. } \\
\text { - Cirugías prolongadas como MEEK o microcirugía deberán ser analizadas caso a caso según condiciones del paciente } \\
\text { y situación epidemiológica del Servicio en el momento. }\end{array}$ \\
\hline $\begin{array}{l}\text { Medidas } \\
\text { de seguridad } \\
\text { para operar }\end{array}$ & $\begin{array}{l}\text { - } \quad \text { Desconectar la presión positiva del pabellón. } \\
\text { - } \text { de recibir al paciente (Figura 1). } \\
\text { - } \quad \text { Minimizar la entrada y salida de la sala de operaciones durante la cirugía. } \\
\text { - Celulares, fichas clínicas u otros artículos personales quedan fuera del pabellón quirúrgico. No utilizar accesorios } \\
\text { (aros, cadenas, anillos). } \\
\text { - } \quad \text { Uso de electrobisturí monopolar con sistema de aspiración de humo incorporado al lápiz, intensidad de coagulación } \\
\text { en } 20 \text { o el voltaje más bajo posible y en pulsos cortos de } 2 \text { a } 3 \text { segundos. } \\
\text { - } \quad \text { Capacitación diaria de uso, retiro y reúso de EPP por enfermera de Pabellón al Equipo Quirúrgico. } \\
\text { - } \quad \text { Pasillo completamente despejado para traslado de ida o vuelta de cama y paciente. } \\
\text { - } \quad \text { Aseo terminal del pabellón entre cada paciente. } \\
\text { Aseo de la cama y la unidad del paciente mientras este es operado, el cual será revisado con máquina de bioluminis- } \\
\text { cencia. }\end{array}$ \\
\hline $\begin{array}{l}\text { Elementos } \\
\text { de protección } \\
\text { personal (EPP) }\end{array}$ & $\begin{array}{l}\text { - } \quad \text { Mascarilla N95 + antiparras + escudo facial o máscara de snorkel fullface adaptada a EPP + mascarilla quirúrgica (Fi- } \\
\text { guras } \mathbf{2} \text { y } \mathbf{3} \text { ). } \\
\text { - } \\
\text { - }\end{array}$ \\
\hline $\begin{array}{l}\text { Flujo de entrada } \\
\text { y salida del pabellón }\end{array}$ & $\begin{array}{l}\text { - El cirujano deberá colocarse todos los EPP en la puerta de entrada al quirófano, supervisado por enfermera de pa- } \\
\text { - } \quad \text { Lellón. } \\
\text { ril. } \\
\text { - } \quad \text { Procedimiento quirúrgico según programación (evitar prolongar cirugía por más de } 2 \text { a } 3 \text { horas). } \\
\text { - } \text { - Hirujano/funcionario se retira delantal quirúrgico, pechera y botas en la puerta de salida, dentro del quirófano. } \\
\text { - Higiene de piel expuesta en contorno de la cara, con compresa + alcohol gel. } \\
\text { - } \quad \text { Retiro de antiparras/escudo facial o máscara, se dejarán en caja plástica dispuesta para eso en la puerta de salida del } \\
\text { quirófano, supervisado por enfemera. } \\
\text { Salida del quirófano directo al sector de vestidores para cambio de ropa, sin tener contacto con otras personas o } \\
\text { procedimientos. } \\
\text { Funcionarios que entregan al paciente en Box: anestesista + enfermera de pabellón (con EPP todavía puestas) + au- } \\
\text { xiliar limpio, al entregar paciente, ambas personas deben retornar a pabellón para el retiro y deshecho adecuado de } \\
\text { EPP. }\end{array}$ \\
\hline
\end{tabular}

PCR (+) para SARS-CoV-2 que se encuentran aislados en UCI; cuatro de ellos están conectados a ventilación mecánica invasiva; todos en distintas etapas de evolución de sus quemaduras, requiriendo ingreso a pabellón cada 5-7 días según necesidad. Para poder dar continuidad a su tratamiento, la planificación de la actividad quirúrgica en el Servicio se organizó de la manera que se detalla en la Tabla 1.

\section{Preparación del quirófano para operar a paciente $\mathrm{CO}$ - VID-19(+) o sospecha (Figura 1).}

Elementos de protección personal (EPP) (Figuras 2, 3 y 4).

\section{RESULTADOS}

Se han realizado 28 cirugías en las 3 semanas desde el ler caso, de las cuales 10 han sido en pacientes COVID-19 (+) como se muestra en la Tabla 2:

Desde la semana 1 hasta la fecha, no hemos tenido casos de contaminación cruzada entre pacientes COVID (+) y COVID (-) y tampoco contagio de ningún miembro del equipo quirúrgico.
TABLA 2. Cirugías realizadas en Servicio de Quemados - HUAP desde caso índice.

\begin{tabular}{|c|c|c|c|c|c|}
\hline \multirow{2}{*}{ Semana } & \multirow{2}{*}{\begin{tabular}{c}
\multirow{2}{*}{ de } \\
cirugías
\end{tabular}} & \multirow{2}{*}{$\begin{array}{c}\text { Cirugías } \\
\text { COVID (+) }\end{array}$} & \multicolumn{3}{|c|}{ Complejidad de quemadura } \\
\cline { 4 - 6 } & & & Grave & Crítico & $\begin{array}{c}\text { Sobrevida } \\
\text { excepcional }\end{array}$ \\
\hline 1 & 6 & 2 & 4 & 2 & 0 \\
\hline 2 & 11 & 5 & 6 & 4 & 1 \\
\hline 3 & 11 & 3 & 4 & 7 & 0 \\
\hline Total & 28 & 10 & 14 & 13 & 1 \\
\hline
\end{tabular}

\section{DISCUSIÓN}

Una de las primeras medidas tomadas en el Servicio de Quemados, antes de contar con nuestro primer caso, fue dividir el equipo de cirujanosde cada día en dos grupos (normalmente operamos un gran quemado entre 5 a 6 personas), precisamente con el objetivo de evitar el contagio simultáneo, como fue lo que ocurrió el día 1 en que se operó a la paciente índice que dio PCR (+) al día siguiente. En esa oportunidad debió irse a "cuarentena preventiva por 14 días" todo el equipo quirúrgico que participó de la cirugía: 3 cirujanos, 1 anestesista, 1 enfermera de pabellón, 1 técnico de anestesia, 1 arsenalera y 1 pabellonera.

La razón de establecer 2 hs como máximo de tiempo 


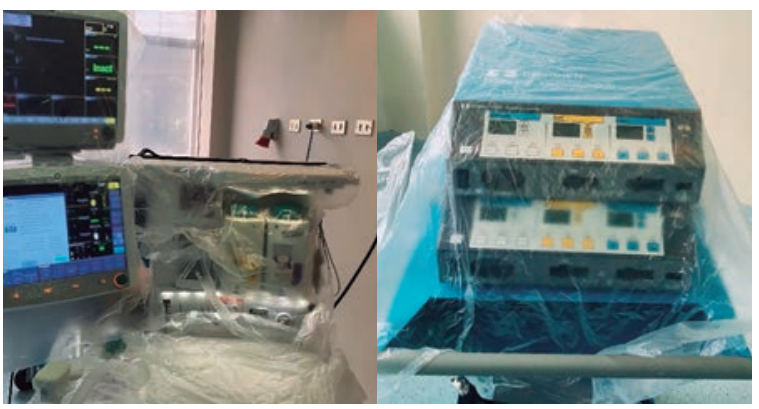

Figura 1. Máquina de anestesia y electrobisturí cubiertos con plástico, protegidos para cirugía.

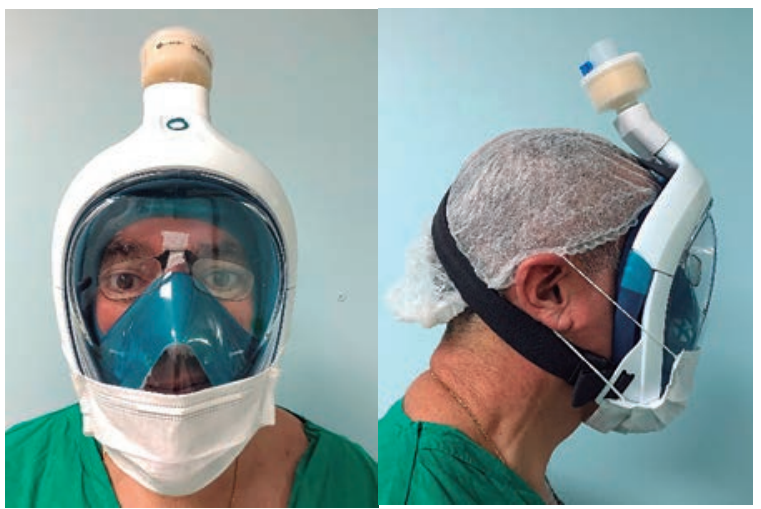

Figura 3.- Protección facial con Máscara Fullface: Máscara de Snorkel modificada con filtro HME $^{3}$.

quirúrgico se debe fundamentalmente a la capacidad de resistencia física del personal a las condiciones ambientales generadas al operar un paciente COVID-19 (+); con las primeras cirugías pudimos darnos cuenta que operar con todos los EPP (máscaras con triple sello que restringen la ventilación normal + ropa desechable de plástico + la ropa quirúrgica) y el tener que operar en un pabellón a $25^{\circ} \mathrm{C}$ de temperatura ambiente para evitar la hipotermia del paciente gran quemado genera en los operadores un alto grado de deshidratación, sensación de ahogo, desvanecimiento y mayor riesgo de quiebre en las medidas de seguridad a la hora de retirarse los EPP y abandonar el quirófano COVID, momentos críticos en los que se han presentado reportes de "contagio en el personal sanitario" 4,5 .

En relación a las medidas de seguridad para operar un paciente quemado ${ }^{6}$, la bibliografía publicada hasta el momento describe que son denominados "procedimientos de alto riesgo" en cirugía de un paciente con coronavirus: la intubación, el uso de electrobisturí y de herramientas a alta velocidad (sierras con motor, dermatomo) debido a la capacidad de aerolización de partículas. Se ha demostrado que el humo del electrocauterio alberga partículas intactas de bacterias y virus?

Los EPP reutilizables dejados en la caja plástica antes de salir de pabellón son posteriormente limpiados por personal técnico del servicio (quien estará vestido con: mascarilla quirúrgica + pechera + guante + antiparras

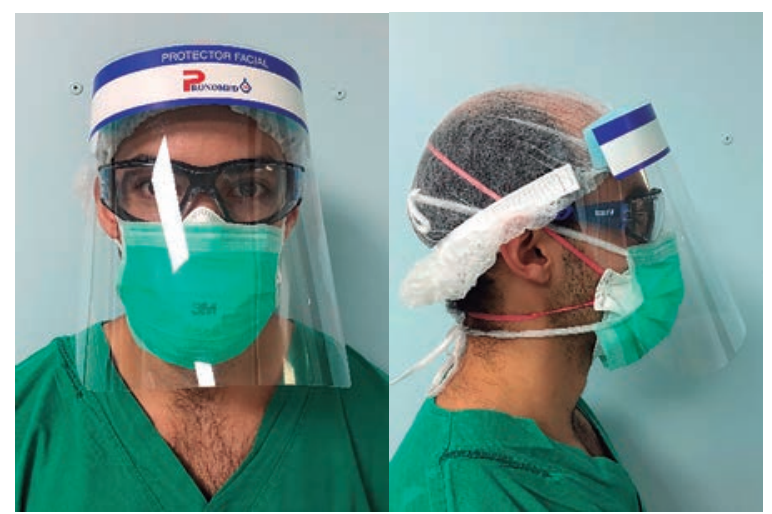

Figura 2. Protección facial clásica: mascarilla N95 + Mascarilla quirúrgica (para proteger N95 y permitir su uso continuo 24 hs) + antiparras + escudo facial.

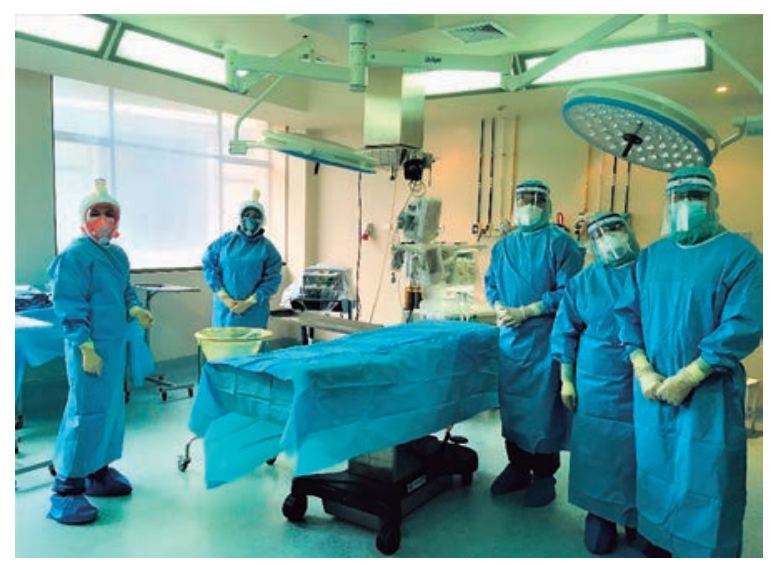

Figura 4. Equipo quirúrgico, con las respectivas EPP e indumentaria quirúrgica estéril.

o escudo) y después guardados en la una caja limpia para su uso en próxima cirugía.

\section{CONCLUSIONES}

Chile, al igual que casi toda Latinoamérica, se encuentra actualmente en sus semanas peak de contagio. La evolución epidemiológica que pueda seguir nuestra población es solo medianamente extrapolable de lo ocurrido en Europa; en este lado del mundo estamos recién comenzando el invierno y. por estadísticas propias, es precisamente ahora cuando comienza a la temporada alta de quemaduras de Invierno (sistemas de calefacción defectuosos, explosiones de balones de gas, escaldaduras, etc.). Por lo tanto, la combinación de "confinamiento" en pandemia por coronavirus y potenciales quemaduras nos obliga estar atentos y a mantener un estricto régimen de medidas de seguridad en el quirófano de quemados.

\section{AGRADECIMIENTOS}

A las 127 personas que trabajan día a día en nuestro Servicio de Quemados del Hospital de Urgencia de Asistencia Pública, exponiendo su propia integridad física en pos de los pacientes grandes quemados. 


\section{BIBLIOGRAFÍA}

1. World Health Organization. https://www.who.int/emergencies/diseases/novel-coronavirus-2019/situation-reports.

2. Guías Clínicas AUGE Gran Quemado - Marzo 2016. Subsecretaría de Salud Pública. División de Prevención y Control de Enfermedades Departamento AUGE y de Coordinación Evidencial y Metodológica.

3. Pneumask Stanford Project.https://docs.google.com/document/d/ 1J22le3dBZBnNDXGIJLRb38z7v7LaOjKFDeN9fOtFeKY/edit

4. Takhar A, Walker A, Tricklebank S, Wyncoll D, Hart N, Jacob T, et al. Recommendation of a practical guideline for safe tracheostomy during the COVID 19 pandemic. European Archives of Oto-Rhino-Laryngology. https://doi.org/10.1007/s00405-020-05993-x
5. Herron JBT, et al. Personal protective equipment and COVID 19risk to healthcare staff? Br J Oral MaxillofacSurg 2020 https://doi. org/10.1016/j.bjoms.2020.04.015.

6. Siyuan M, Zhiqiang Y, Yizhi P, Jing C, Haisheng L, Qizhi L, et al. Experience and suggestion of medical practices for burns during the outbreak of COVID-19. https://doi.org/10.1016/j.burns.2020.03.014.

7. Brat G, Hersey S, Chhabra K, Gupta A, Scott J. Protecting Surgical Teams During the COVID-19 Outbreak: A Narrative Review and Clinical Considerations. Annals of Surgery: April 17;2020. doi: 10.1097/ SLA.0000000000003926 